\title{
THE DIAGNOSTIC VALUE OF THE PROTEIN EXCRETION PATTERN IN VARIOUS TYPES OF PROTEINURIA
}

\author{
BY \\ D. WOLVIUS AND J. C. M. VERSCHURE \\ With the Technical Assistance of \\ F. C. M. HOEFSMIT \\ From the Medical Department, University Hospital, Utrecht, Netherlands
}

(RECEIVED FOR PUBLICATION FEBRUARY 6, 1956)

Since the development of paper electrophoresis, fresh attention has been paid to the investigation of urinary proteins. Some authors have pointed to the diagnostic value of the excretion pattern in cases of multiple myeloma (Slater and Kunkel, 1953 ; Fauvert and Hartmann, 1954). Apart from multiple myeloma, little has been said about the diagnostic value of the protein pattern in the urine in other types of proteinuria.

The purpose of the present investigation was: (1) To obtain further experience concerning the mutual ratio of urinary proteins in various types of proteinuria with the help of paper electrophoresis : (2) to test the usefulness of this method of investigation for clinical purposes. Special attention was paid to postural proteinuria.

\section{Material and Methods}

The Table gives a survey of the cases discussed in this paper, divided into the different types of proteinuria. From these 50 cases, 81 diagrams of serum and urinary proteins were made. Most patients were

TABLE

SURVEY OF PATIENTS INVESTIGATED

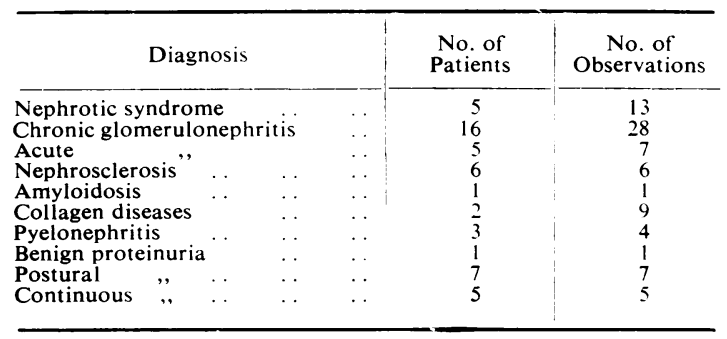

studied under adequate ward conditions; some. however, were investigated in the Out-patient Department.

The samples of serum and urine to be analysed were taken from random specimens based upon the observations of Antweiler (1952) and Bubb and Pedrazzini (1949), who found no change in the mutual ratio of serum proteins during the course of the day. Moreover, Bing (1936) and Lathem, Roof. Nickel. and Bradley (1954) noted the stability of the protein excretion pattern.

The method of paper electrophoresis used for the analysis of serum and urine is a micro-technique which has been fully described by us (Wolvius and Verschure. 1955). With this technique it is possible to obtain a good resolution of the various protein bands within four hours, the $\alpha$ globulins being well separated from the albumins. The tank in which the analyses are performed is large and makes it possible to perform nine analyses of serum or urine at a time. The strips of filter paper (Whatman 1) are stained with azocarmine B (Bayer) and afterwards washed in $10 \%$ acetic acid under standardized conditions. The mutual ratio of protein fractions is determined bi cutting out the bands and extracting them in $5 \mathrm{ml}$. of $0.1 \mathrm{NaOH}$. The extinction of each solution is determined with the Beckmann spectrophotometer.

We have shown in the former paper (Wolvius and Verschure. 1955) the good reproducibility of this method of paper electrophoresis for the quantitative estimation of serum protein fractions. Moreover, the reliability of the analysis of urinary proteins could be cemonstrated, and the results are comparable to those of serum. It was found necessary to concentrate the urines until they contained at least $1.5 \mathrm{~g} .{ }_{\circ}^{\circ}$ protein before they could be analysed. By analysing a urine with a lower concentration of protein, an apparent fall of the relative albumin percentage was observed.

\section{Results and Discussion}

The Pattern of Urinary Proteins in Types of Proteinuria.-In all of the 81 diagrams of urinary proteins, an albumin band as well as an $\alpha, \beta, \gamma-$ globulin band could be observed. Fauvert and Hartmann (1954) pointed to the absence of the globulins in the urine of a patient in the early stage of the nephrotic syndrome. The present series includes five cases of the nephrotic syndrome, some of which were in the early stage. In these diagrams also all the major components of 
the serum appeared to be present. In none of the 81 diagrams of urinary proteins could a protein band be found without a counterpart in the serum, as was observed by Slater and Kunkel (1953).

In seven instances, the result was positive on acetic acid bodies. The diagrams of these urines did not show any qualitative differences compared with those urines in which this test appeared to be negative.

In Fig. 1 all the relative albumin percentages, divided into the different types of proteinuria, are given. By comparing the values obtained, certain differences may be noted between various renal disorders. The highest relative albumin percentages (90-82) were found in five cases of continuous proteinuria which were found accidentally. These patients had no complaints and no history of renal disease. On physical examination no abnormalities could be detected; there were no urinary sediment abnormalities, the renal function appeared to be unimpaired, and a normal picture was obtained on intravenous pyelography. Though the exact nature of this type of proteinuria remains unexplained these cases may represent recovered or latent examples of chronic glomerulonephritis (King, 1955) and in this paper is designated "continuous proteinuria."

The present study includes the results of the quantitative estimation of urinary proteins in seven cases of postural proteinuria. As already stated by King (1955) and Löwgren (1955), these urines contain a relatively large amount of globulins. In the present series, the relative albumin percentages ranged from 63 to 73 . Similar observations were made in another nine patients, and these results will be published in another paper.

In three cases of pyelonephritis the relevant albumin percentage ranged from 24 to 63 . Similar observations were made by Boyce, Garvey, and Norfleet (1954). These authors, working with the Tiselius method of electrophoresis, suggested mucoproteins in the region of the alpha-globulins in the urine of these patients.

In most types of proteinuria a considerable variation was found in the relative albumin percentages. This was especially marked in the nephrotic syndrome (60-84), chronic glomerulonephritis (33-86), nephrosclerosis (55-77), and pyelonephritis (24-63). The series of cases of acute nephritis, which included five patients, all convalescent, showed a variation of from 70 to $82 \%$. Two patients suffering from lupus erythematosus and periarteritis nodosa showed a relative albumin percentage ranging from 54 to 70 . These variations will probably increase by extending the number of observations. It can easily be seen from Fig. 1 that as

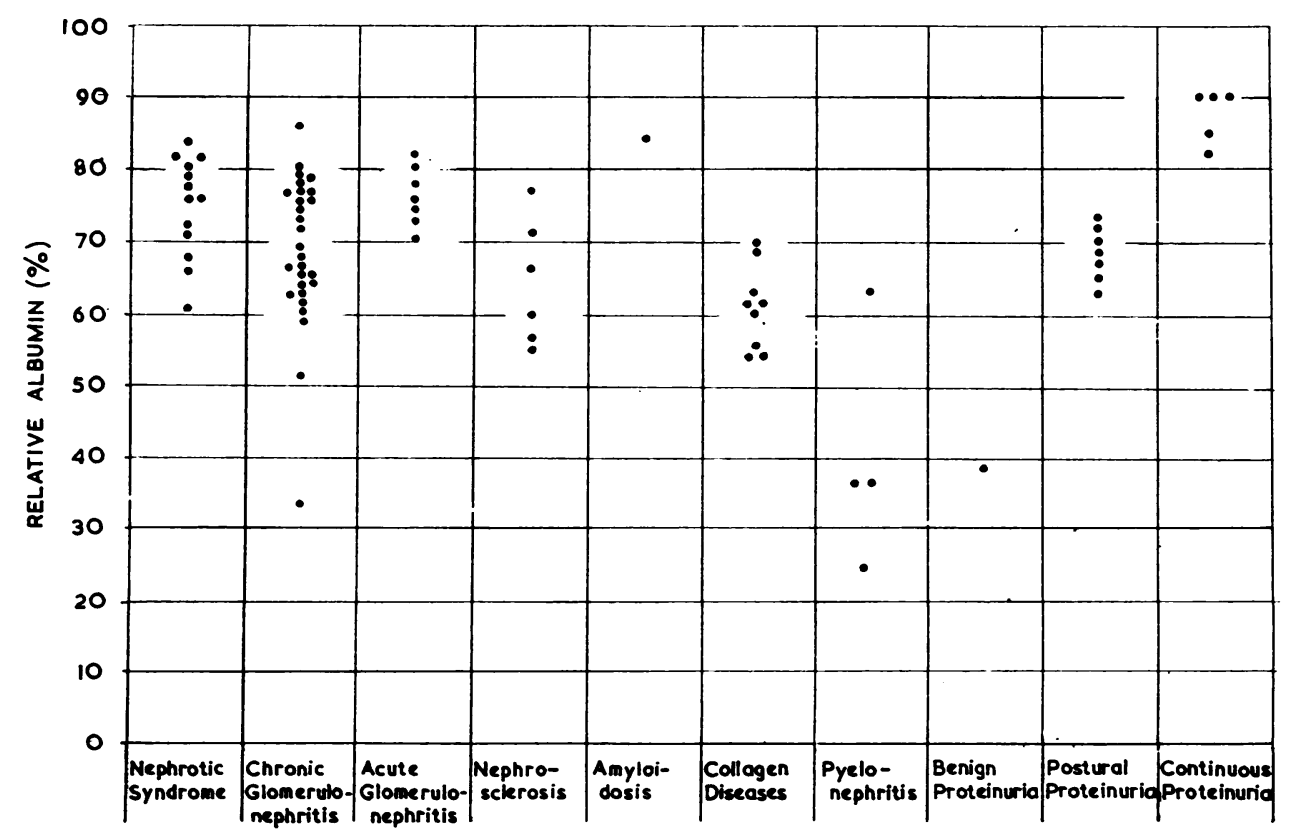

FIG. 1.-Survey of relative albumin percentages in urine of patients investigated. 
a consequence of these variations no pathognomonic albumin-globulin ratio appears to exist.

Globulin-Albumin Clearance Ratio in the Various Types of Proteinuria.-Bing (1936) was one of the first to point to the relation of the protein excretion pattern and the amount of the various protein fractions in the serum. Hardwicke and Squire (1955) expressed this relation by determining the clearance of the separate globulin fractions as a percentage of the albumin clearance. By determining, however, the clearance ratio of the total globulins to the albumins this error will not exceed $12 \%$. In the present study no pathognomonic differences could be found in the mutual behaviour of the separate globulin fractions in the various types of proteinuria (Wolvius, 1955). For reasons stated above, the clearance ratio of the joint globulins to the albumin $(\mathrm{G} / \mathrm{A})$ was chosen in the present study. This clearance ratio was determined in the following way:

$$
\mathrm{C}_{\mathrm{alb}}=\frac{\mathrm{U}_{\mathrm{alb}} \times \mathrm{V}}{\mathrm{Palb}}
$$

Where $\mathrm{C}_{\mathrm{alb}}$ is the clearance of the albumins

$\mathrm{U}_{\mathrm{alb}}$ is the absolute concentration of the urinary albumins

$\mathrm{V}$ is quantity of urine per unit of time

$P_{a l b}$ is the absolute concentration of the serum albumins
The globulin-albumin clearance ratio is thus:

$$
\frac{\mathrm{C}_{\text {glob }}}{\mathrm{C}_{\mathrm{alb}}}=\frac{\frac{\mathrm{U}_{\text {glob }} \times \mathrm{V}}{\mathrm{P}_{\text {glob }}}}{\frac{\mathrm{U}_{\mathrm{alb}} \times V}{\mathrm{P}_{\mathrm{alb}}}}
$$

Formula (2) can be simplified to:

$$
\frac{\mathrm{U}_{\text {glob }}}{\mathrm{P}_{\text {glob }}} \times \frac{\mathrm{P}_{\mathrm{alb}}}{\mathrm{U}_{\mathrm{alb}}}
$$

In Fig. 2 all the globulin-albumin clearance ratios are given divided into the various types of proteinuria. In most cases, a clearance ratio was found smaller than 1 , which proves the fact that in a majority of cases more albumins than globulins are excreted. Though considerable differences were found in the globulin-albumin clearance ratio (0.1 to 2.0$)$ no correlation between this ratio and the amount of protein excreted could be found.

In determining the globulin-albumin clearance of a given patient on different instances, no large variations could be detected. However, small variations nearly always appeared to be present. Small variations were also observed during an intravenous administration of blood and homogenous human albumins; in one case of chronic glomerulonephritis the globulin-albumin clearance ratio ranged under these circumstances from 0.4

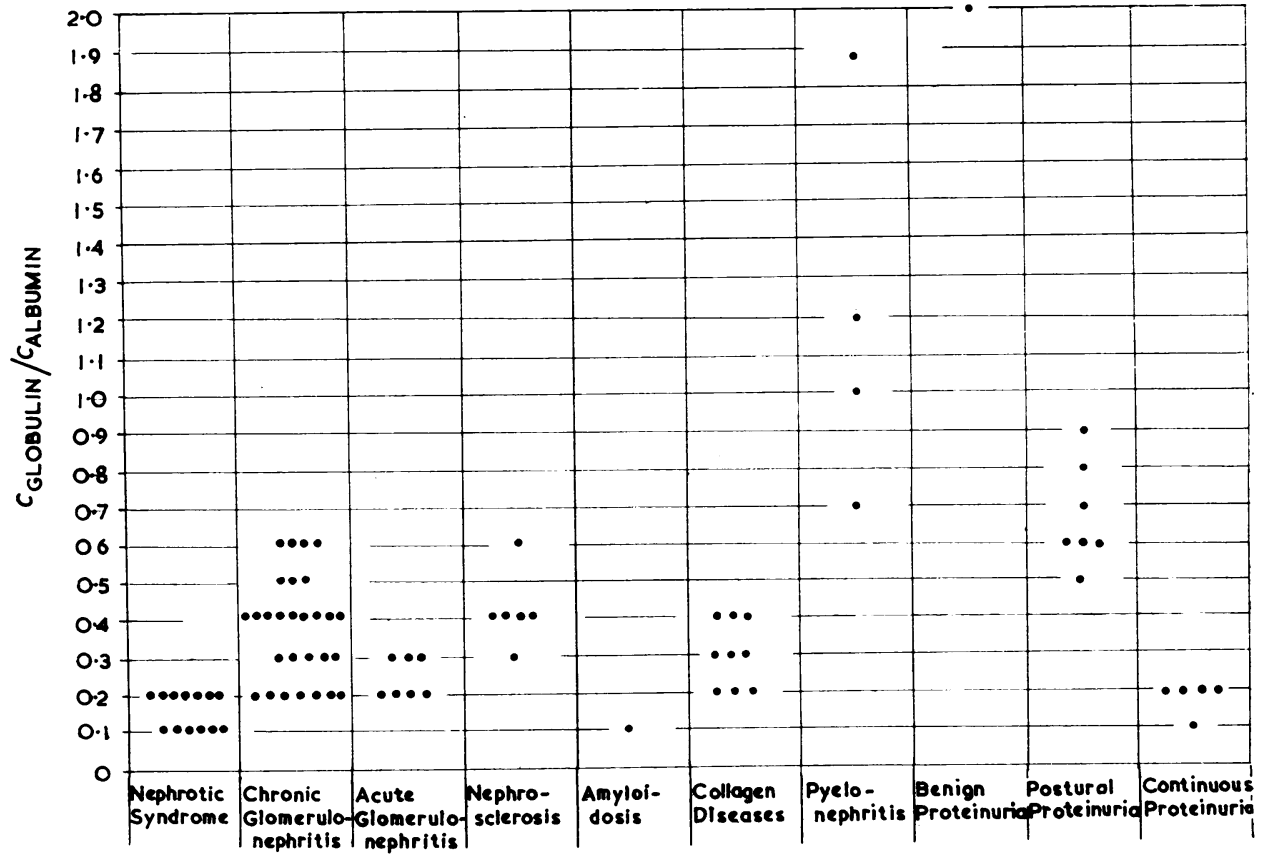

FIG. 2.-Survey of G A clearance ratios in patients investigated. 
to 0.6. In general these variations did not show any correlation with the course of the disease. In only one patient could such a correlation be demonstrated. During his first period in hospital the clinical picture was that of the nephrotic syndrome, and a clearance ratio of 0.1 to 0.2 was found. Ten months later the picture was that of a chronic glomerulonephritis with uraemia, and the clearance ratio was 0.3 to 0.4 .

Comparing the globulin-albumin clearance ratios of different patients all suffering from the same disease, there appears in general to be no larger variation than was seen in any one individual. This especially holds true for the nephrotic syndrome ( 0.1 to 0.2$)$, acute glomerulonephritis $(0.2$ to 0.3$)$, nephrosclerosis $(0.3$ to 0.6$)$, the collagen diseases $(0.2$ to 0.4$)$, and continuous proteinuria (0.1 to 0.2$)$. The somewhat larger variations in the group of chronic glomerulonephritis are due to the somewhat lower ratio $(0.2)$ in cases of nephritis in a nephrotic state than in cases with a moderate loss of proteins $(0.3$ to 0.6$)$. In the present series, the clearance ratios in cases of postural proteinuria range from 0.5 to 0.9 .

In comparing the globulin-albumin clearance ratios found in various diseases (Fig. 2) the differences become more apparent than when the relative albumin percentages are used. In most cases of organic renal disease the differences in general remain rather small and they will not be of much practical importance. The higher clearance ratios in cases of collagen diseases in comparison with the ratio in the nephrotic syndrome may, however, be mentioned. The difference is the more interesting since one patient with lupus erythematosus showed a protein loss of up to $15 \mathrm{gr}$. a day. The very high clearance ratios in cases of pyelonephritis need further investigation, especially in reference to the probable presence of many mucoproteins. It is thought possible, however, that the high clearance ratios in cases of pyelonephritis may be of diagnostic aid. King (1955) recently emphasized the difficulty in differentiating pyelonephritis from glomerulonephritis.

There appeared to be a considerable difference between the clearance ratios in cases of postural proteinuria and continuous proteinuria.

Little can be said about the correlation between the severity of the renal disorder to which the proteinuria is due and the globulin-albumin clearance ratio. The severity of the renal disorder and the globulin-albumin clearance ratio do not parallel one another.

\section{Summary and Conclusions}

After an earlier report on the reliability of the quantitative estimation of serum and urinary proteins by means of a micro-technique for paper electrophoresis, the present paper gives the results of 83 analyses of sera and urines from 50 patients suffering from various types of proteinuria.

In all of the 81 diagrams of urinary proteins all the major components of the serum appeared to be present. In none was a protein band without a counterpart in the serum found.

Though certain differences could be found in the urine albumin-globulin ratios of the various types of proteinuria, no pathognomonic ratio appeared to exist.

In each urine sample the clearance ratio of the total globulins to the albumins was determined. In this way more distinct differences could be observed between the various types of proteinuria, but no pathognomonic clearance ratios could be detected. The clearance ratios found in two cases of pyelonephritis were distinctly higher than in the other cases of organic renal diseases. Though these high clearance ratios need further investigation, it is thought probable that this fact may be of clinical value.

There proved to be a considerable difference in the clearance ratio in cases of postural proteinuria and in cases of continuous proteinuria. This difference undoubtedly will be of clinical importance.

During the present investigation no correlation in general could be found between the clearance ratio of the globulins to the albumin and the severity of the renal disorder to which the proteinuria was due.

During the preparation of this paper a number of observations were made of cases of benign proteinuria resulting from physical exertion. The protein excretion pattern in these cases strongly resembled that seen in postural proteinuria. G/A clearance ratios were found ranging from 0.3 to 1.7 .

\section{REFFRENCES}

Antweiler, H. J. (1952). Die quantitative Elektrophorese in der Medizin. Springer, Berlin.

Bing, J. (1936). Studies on Proteinuria. Levin and Munksgaard, Copenhagen. (Acta med. scand., Suppl. 76.)

Boyce, W. H., Garvey, F. K., and Norfleet, C. M. (1954). J. clin. Invest., 33, 1287.

Bubb, W., and Pedrazzini, A. (1949). Schweiz. med. Wschr.. 79, 167. Fauvert, R., and Hartmann, L. (1954). Les Albuminuries. Masson, Paris.

Hardwicke, J., and Squire, J. R. (1955). Clin. Sci., 14, 509.

King, S. E. (i955). Ann. intern. Med., 42, 296.

Lathem, W., Roof, B. S., Nickel, J. F., and Bradley, S. E. (1954). J. clin. Invest., 33, 1457.

Löwgren, E. (1955). Acta med. scand., Suppl., 151, 300.

Slater, R. J., and Kunkel, H. G. (1953). J. Lab. clin. Med., 41, 619. Wolvius, D. (1955). Thesis, University of Utrecht.

and Verschure, J. C. M. (1955). Journal of Clinical Pathology, 